\title{
Caries and Periodontitis: Contesting the Conventional Wisdom on Their Aetiology
}

\author{
Firoze Manji ${ }^{\mathrm{a}}$ Gunnar Dahlen ${ }^{\mathrm{b}}$ Ole Fejerskov ${ }^{\mathrm{c}}$ \\ a Daraja Press, CSP Mozart, Montreal, QC, Canada; ${ }^{b}$ Department of Oral Microbiology and Immunology, Institute of \\ Odontology, Sahlgrenska Academy, University of Gothenburg, Gothenburg, Sweden; 'Department of Biomedicine, \\ Faculty of Health, Aarhus University, Aarhus, Denmark
}

\section{Keywords}

Aetiology · Dental caries · Oral health · Periodontitis

\begin{abstract}
We review the literature on the oral microbiome and the role of the microbiota in the development of dental caries and periodontitis. While most research has been focused on identifying one or more specific determinants of these diseases, the results have provided limited predictive value and have not been able to explain the variation in the distribution of these diseases observed in epidemiological or clinical studies. Drawing on existing knowledge about the nature of the oral microbiota, we suggest that a stochastic model based on the Weiner process provides simple and parsimonious explanations for the pathogenesis of both caries and periodontitis, making few assumptions, and providing explanations for phenomena that have hitherto proved difficult, or have required complex arguments, to explain. These diseases occur as the result of the dental hard tissues and periodontal tissues integrating the random "noise" caused by normal metabolic activities of commensal microorganisms in the dental biofilm. The processes that result in the progression and regression of caries and periodontitis may
\end{abstract}

be considered as "natural," rather than pathological, even if, when left unchecked over long periods of time, they can result in the development of pathologies. The likelihood of progression or regression can be influenced by other determinants, but these processes will nevertheless occur in the absence of such influences. The distributional characteristics of the model approximate the findings of epidemiological studies indicating that, for both caries and periodontitis, there will be few sites affected in the early period after the eruption of the permanent dentition, but in those older there is an almost linear relationship with increasing age; furthermore, the longer a site survives without being affected, the less likely that it will be affected. We discuss the clinical and public health importance of these findings.

() 2018 S. Karger AG, Basel

Globally, oral health is not improving, except in the Scandinavian countries. This is despite intensive focus over the last half a century on understanding the aetiology of the two major oral diseases, caries and periodontitis, in relation to oral microbiota [Socransky and Haffajee, 1992; Darveau, 2010; Costalonga and Herzberg, 2014; Gomez and Nelson, 2017]. This is also despite the devel-

\section{KARGER}

(c) 2018 S. Karger AG, Basel

E-Mail karger@karger.com

www.karger.com/cre
Ole Fejerskov, Professor Emeritus

Department of Biomedicine, Faculty of Health, Aarhus University

Wilhelm Meyers Allé 3

DK-8000 Aarhus C (Denmark)

E-Mail of@ biomed.au.dk 
opment of increasingly sophisticated technologies in the treatment of these diseases. Dental caries is the most prevalent disease in humans, and the costs associated with conventional treatment of caries and periodontal diseases are enormous [Listl et al., 2015]. Similarly, some degree of periodontal breakdown in adults is almost ubiquitous, and the costs of applying conventional treatment strategies, even amongst children, are considered to be excessive [Listl et al., 2015].

A major question for oral health research has been to determine what role bacteria play in the development of caries and periodontitis. Numerous studies have searched for the specific microorganisms, the specific composition or specific function of the oral microbiome/microbiota [Socransky et al., 1998; Takahashi and Nyvad, 2011] and with a focus on the supragingival and subgingival dental plaque that is formed on the surface of teeth. This has led to a cascade of research on associations between a number of bacterial species and the diseases, although the aetiological role of any of the associated microorganisms has hitherto proved to be illusive. Many hypotheses have been proposed during the last several decades to explain the role of specific microorganisms in these diseases [Rosier et al., 2014] but these have proved to have poor predictive value clinically or epidemiologically. It seems that the role of the microorganisms in the dental biofilm is still far from understood.

For clarity, we make a distinction between microbiota, which includes living (viable) microorganisms, and the microbiome, which includes all available genomes including dead and living microorganisms or free DNA in a habitat. We use the term biofilm to refer to groups of microorganisms in which cells stick to each other and on a surface. These adherent cells become embedded within a slimy extracellular matrix that is composed of extracellular polymeric substances. Dental biofilms are those adhering to tooth surfaces and include host glycoproteins/ proteins (previously termed pellicle) that are immediately formed on a clean surface. Finally, the term dental plaque is a clinical term for the soft deposits that are visible on tooth surfaces.

The aim of this paper is, through reviewing the literature on the oral microbiome and its association with caries and periodontal diseases, to consider an alternative perspective on the aetiology of these diseases which does not depend on hypotheses about the specific composition of the dental biofilm, nor on postulating the role of one or other specific aetiological agent, nor on changes in ecological imbalances within the microbiota. Rather, we suggest that both caries and periodontitis are the conse- quence of normal metabolic activities of commensal organisms within the microbiota. These biological processes are ubiquitous and occur lifelong. The outcome (loss of mineral and cavity formation and loss of periodontal attachment) cannot, in a true sense, be prevented, but the processes may be controlled over time so that caries and periodontitis may not progress to a stage where teeth are lost. The features of the development and progression of both diseases can be modelled using a stochastic model whose statistical features are consistent with the clinical and epidemiological features of caries and periodontitis. We believe that this alternative perspective offers the possibility of providing effective and simple public health strategies for the control of these diseases.

\section{The Human Oral Microbiome}

The mouth constitutes the main portal entrance for microorganisms to the entire gastrointestinal tract. Each part of the gastrointestinal tract has its own site-specific microbiome regulated by the physiological and other environmental factors that characterize each particular ecological unit (habitat). These microbial habitats and their genomes constitute the characteristic microbiome for each niche, where the microorganisms live in symbiosis or microbial homeostasis [Marsh, 2004] with the host and constitute the symbiont. Altogether, we (humans) have evolved into what might be considered as a "superorganism," a holobiont [Kilian et al., 2016], implying that the different human microbiomes can be considered parts of ourselves.

The oral microbiome comprises site-specific microbiomes of the oral mucosa, the dorsum of the tongue, and the tooth surface along the gingival margin, while saliva contains essentially a mixture of microorganisms detached from the microbial biofilms present on all oral surfaces. Similarly, all body surfaces - skin, nose, ears, eyes and genitals, etc. - have their own characteristic microbiota [Wilson, 2005].

There is a continuous pressure from "new" microorganisms from the surroundings, from harmless organisms to exogenous primary pathogens that try to establish themselves in the body. Primary pathogens refers here to microorganisms that can cause disease in an otherwise healthy individual, while opportunistic pathogens are microorganisms that can cause infectious disease in a host with, for example, depressed systemic resistance (immunodeficiency). Early oral microbiome studies using sequencing analysis of $16 \mathrm{~S}$ rRNA genes disclosed a number 
of unknown phylotypes, many of which had not yet been cultured [Dewhirst et al., 2010]. Using newer molecular microbiological methods such as the next-generation high-throughput sequencing approach has disclosed a considerable number of microbial species and revealed new insights into the complex composition and functioning of the oral microbiome [for a review, see Nyvad et al., 2013]. It is estimated that the oral microbiome contains about 700 microbial species and 19,000 phylotypes (genotypes) [Keijser et al., 2008]. Others claim that we probably deal with more than 1,000 species, which make the oral microbiome the most diverse of the human body. This species diversity is highly variable amongst individuals depending on how and where the sample for analysis is taken [Xu et al., 2015]. Moreover, age, diet, oral hygiene level, living conditions, and cultural habits influence the variation. However, once established on the tooth surface after eruption of the permanent teeth, an individual's normal microbiome is in a steady-state condition and stable unless the immune system is challenged or a dysbiosis develops. Examples of such conditions are AIDS or following medication with cytotoxic drugs in cancer treatment, where immunocompromised individuals commonly experience an overgrowth of yeast (Candida) or enterics in the oral cavity [Samaranayake et al., 2009; Dahlen, 2009]. Moreover, at any given location modification of the composition of the microbiota may occur caused, for example, by antibiotic treatments [Crielaard, 2013]. Once the balance of the immune system is re-established, the oral microbiota remains stable and opportunistic infections/dysbiosis can be prevented [Zanoni and Gandhi, 2014]. The term "dysbiosis" is sometimes used to refer to the changes in the composition of the microbiota in particular niches (for example, those found in deep periodontal pockets), but such changes are more likely an adaptation of the normal microbiome to a modified microenvironment rather than strictly a dysbiosis, a term that normally refers to microbial imbalance or maladaptation within the microbiome.

\section{The Core Microbiome}

The composition of the microbiome can be described at different levels - from phylum level to genus, species, and even genotype level, depending of the purpose. On phylum level, the oral microbiome is dominated by Firmicutes but also include a high level of Actinobacteria, Proteobacteria, Bacteroidetes, Fusobacteria, and these are common for humans (as distinct from animals), and clearly it is distinct from those found in other body habitats [Aas et al., 2005; The Human Microbiome Project Consortium, 2012].

At present, more than 700 prokaryotic taxa (species) have been detected in the human oral cavity, many of which have not been isolated with common culture methods [Dewhirst et al., 2010]. The number is steadily growing, when analysing samples from different oral locations, individuals and populations, and by using new technologies for identification [Nyvad et al., 2013]. Some taxa that only occur sporadically are not necessarily part of the colonizing microbiota but are transient microorganisms that just happen to be present at the sampling occasion and are likely to be eliminated soon from the oral cavity. Some less dominating taxa are highly personalized, while others are present in the oral cavity of the entire human populations worldwide and represent the human oral core microbiome [Zaura et al., 2009; Griffen et al., 2011].

The oral cavity is characterized by the predominance of Streptococcus species in all oral niches, i.e. saliva, dorsum of the tongue, the oral mucosa (including pharynx), and dental plaque (supragingival as well as subgingival) of healthy humans, while streptococci are low in other body habitats, such as the stool (which are predominated by anaerobes such as Bacteroides, Bifidobacterium, and Clostridium spp.), vaginal microbiota (lactobacilli), and skin (Propionibacterium, Staphylococcus, Corynebacterium, and Moraxella species) [The Human Microbiome Project Consortium, 2012].

Streptococci are by far the most superior microorganisms for colonization of the oral cavity [Frandsen et al., 1991; Burne, 1998; The Human Microbiome Project Consortium, 2012]. They are the outstanding pioneer species in all oral niches including mucosal surfaces and tooth surfaces after tooth eruption. They are extremely well adapted to the oral cavity by a multitude of receptor interactions with host cells, salivary glycoproteins and other salivary and serum components (agglutination). Streptococci bind to other microbial cells (auto-aggregation, co-aggregation) and to lectins and other food components, for example, polyglucan production from sugars increases the binding capacity of several streptococci [Burne, 1998]. This exceptionally strong binding capacity is far greater than that of other microorganisms that might be transmitted and incorporated in the microbiota. They have a very broad range of biochemical activities including both saccharolytic and proteolytic metabolism and the use of glycoproteins from saliva during periods of starvation to produce both acid and alkaline to regulate the ecology. The streptococci produce bacteriocins, which 
regulate the microbiota and block the space and receptors for more pathogenic bacteria. In addition, the streptococci are generally well adapted and tolerant to environmental changes [Marsh and Devine, 2011]. The final selection of the pioneer species early in life is primarily determined by the host (the newborn child) through its oral receptor pattern and environment. Binding structures and environmental host factors such as mucins, lysozyme, lactoferrin, and host defence peptides (defensins, etc.) constitute a host antimicrobial system (inherent or innate immunity), which consequently play a decisive role in the colonization and regulation of the microbiota [Marsh and Martin, 2009]. The best-suited strains for this selection come from the mother and other family members and explain why certain microbial genotypes occur in some families but not in others [Tinoco et al., 1998].

The oral microbiota/microbiome is further characterized by Veillonella, Haemophilus, and Neisseria spp. and anaerobes such as species of Prevotella and Fusobacterium [Wade, 2013; Costalonga and Herzberg, 2014]. The anaerobes are regularly present in the subgingival plaque, dorsum of the tongue, and saliva even in young healthy individuals, and are frequently found in young children as early as 6 months of age ("early colonizers" [Könönen et al., 1999]. Other anaerobes are late colonizers [Könönen, 1999], while it has been more controversial when socalled putative periodontal pathogens (Porphyromonas gingivalis, Tannerella forsythia and Treponema species) colonize the oral cavity [Darby and Curtis, 2001]. They are not detected regularly in the oral cavity by culture techniques, or are difficult to culture, although it is more likely that they are present in low numbers and will not be detected due to dilution or lack of selective and suitable media [Siqueira and Rocas, 2017]. Using qPCR detection or sequencing studies, these bacteria can be frequently disclosed even in young children [Tanner et al., 2002; Cephas et al., 2011]. The stability in their colonization pattern may thus fluctuate from time to time [van Winkelhoff et al., 2008; Crielaard et al., 2011]. Aggregatibacter actinomycetemcomitans, regarded by some as a putative periodontopathogen, especially in aggressive periodontitis of young individuals [Haubek et al., 2008] (previously designated "localized juvenile periodontitis"), should be an exception due to its facultative anaerobic character, not being sensitive for peroxides (catalase) and acids (low $\mathrm{pH}$ ), having a good adhesion capacity and may successfully compete with streptococci and other early colonizers and can be frequently found in preschool children [Könönen, 1999; Cephas et al., 2011; Dominguez-Bello et al., 2010].

Caries and Periodontitis
Some, including serious pathogens, such as Staphylococcus aureus, Klebsiella spp., Pseudomonas spp. and yeasts (Candida sp.), may occur occasionally in the oral cavity in low numbers. However, they are unable to compete with the streptococci and others of the oral core microbiome. Although they are not regularly found in the oral cavity, and as such are not considered as oral microorganisms, they can under certain circumstances cause serious infections, for example, opportunistic infections or superinfections [Dahlen, 2009]. Opportunistic infections may also occur as a result of microorganisms having an unusual access to the "inside" (sterile host tissues) of the body, for example via trauma, translocation, ulceration or implants (localized opportunistic infection). $\mathrm{Pu}$ tative pathogens, it has been postulated, could be regarded as being present in low numbers in "healthy carriers" and consequently periodontal diseases could be considered as an "opportunistic infection" [Johansson and Dahlen, 2017].

Resident microorganisms of the oral microbiota, which normally are non-pathogenic commensals, have the capacity to become pathogenic when in a different environment. For example, commensal organisms in advanced carious lesions may invade the pulpal tissues where they cause necrosis. The infection may spread into the periapical tissues and surrounding bone, causing an abscess and in some cases more serious infections. Such infections are polymicrobial anaerobic infections with low microbiological specificity [Dahlen, 2017]. Various experimental studies have shown that combinations of such ordinary commensals have a strong ability to produce infections (pus formation and abscesses) once they are inoculated subepithelially in different combinations without including any specific "pathogen," implying that they all have a role in the infectious process [Fabricius et al., 1982; Dahlen et al., 1987].

The core microbiome is important in relation to the development of the host's immune response [Chow et al., 2010]. The oral microbiota becomes established normally during the passage of the child through the vagina. A child delivered by Caesarean section may be at a disadvantage but may acquire the mother's microbiota from contact with her post-partum [Ivanov and Littman, 2011]. The exposure of newborn children to a wide range of antigens is considered important for stimulating the maturation of the immune system [Bessman and Sonnenberg, 2016]. Late acquisition of oral and gut bacteria, or the acquisition of a reduced complexity of the microbiota, may delay immune maturation [Adlerberth and Wold, 2009]. According to the "hygiene hypothesis," the West- 
ern world has reached a hygiene level in the surroundings of the newborn or very young children ( $<3$ years) that may postpone their maturation and predispose the child to allergic reactions later in life [Adlerberth et al., 2007]. It is thought that loss of tolerance or regulation of the gastrointestinal microbiota may be one key factor involved in the development of ulcerative colitis and Crohn disease [Adlerberth and Wold, 2009]. Similarly, it is thought that it may be possible that some forms of periodontal diseases may be the result of loss of tolerance against the subgingival microorganisms [Dahlgren, 2012].

\section{Immune Regulation of the Commensal Oral Microbiota}

The essential function of the immune system is to distinguish between self /not-self. If the core microbiome is part of the super-microorganism and is established during infancy, and if the newborn baby cannot distinguish dangerous from non-dangerous signals, true pathogens may invade and cause infections and maybe even death due to lack of a protective immune response. It is therefore also essential for the newborn baby to be exposed to numerous microorganisms in order to stimulate its own immune system. It is generally considered that the immune system inherited from the mother through the placenta consists mainly of IgG antibodies and it takes between 6 months up to 3 years before the baby's own immune system has reached a functional level, although the neonatal period seems to be most important for the immune adaptation and exposure to microorganisms [Karlsson et al., 1999; Tourneur and Chassin, 2013]. As a result, most of the microorganisms established early in life are regarded by tolerance as commensals and do not provoke a significant immune response so long as they colonize only the epithelial barriers and teeth and do not penetrate the mucosal lining or occur at niches not "normal" for them.

Microorganisms are strongly immunogenic, and thus it seems likely that humans also develop tolerance to microorganisms of the core microbiome in the oral cavity just as they do in the gastrointestinal tract before immune maturation. The colonized commensals may thus be accepted as a part of host, that is, as a part of the "holobiont." This may occur so long as these microorganisms remain on the body surfaces (e.g. mucosa, teeth, and skin). There is a price for this immune naiveté for the host where pathogenic microorganisms invade the epithelial barrier by translocation or trauma, which may result in the sub- sequent development of septicaemia. It is possible that commensals in the oral cavity are more important than previously believed for the rest of the body in stimulating the immune response of the oral mucosal and of the oral pharyngeal lymphoid ring, which guard the entrance to both the gastrointestinal and respiratory tracts from unwanted antigens [Hesselmar et al., 2013].

The colonization of the mucosal surfaces by commensal bacteria immediately post-partum drives the development of the adaptive immune system and tolerance. It appears that commensal bacteria induce a self-limiting humoral mucosal immune response [Cole and Lydyard, 2006]. Numerous attempts have been made to correlate the levels of salivary IgA or serum IgG and IgM antibodies reactive with $S$. mutans or its antigens with caries prevalence (caries lesions) in cross-sectional studies but have failed probably because such correlations may not exist [Aukhil et al., 1988; Pussinen et al., 2011]. Similarly, in periodontitis no clear correlation has been shown between the antibody response and periodontitis [Aukhil et al., 1988; Pussinen et al., 2011]. Chronic infections and commensals give rise to antibodies with low avidity [Cole and Lydyard, 2006] with little protective function. Moreover, the antibody response is highly individual implicating that the antibody reaction against the same antigen and of the same dose could be very different from one person to another. Interestingly, the serum antibody activity only weakly correlates with disease severity and does not significantly correlate with "putative periodontopathogen" counts, although the latter group are highly correlated with other "commensals" [Dahlen et al., 2016]. It appears that the variation in antibody activity across individuals is largely a result of inherent differences in an individual's ability to mount responses, rather than being related to their periodontal status.

Even if the first year of life is most important for the acquisition of an established resident microbiota, there can be changes within the microbiota, and new microorganisms can be established throughout life. Marsh and Martin [2009] proposed that the driving force for the microbiota is to reach a "climax community," where the microbial composition reaches its full complexity and becomes the primary defence barrier against exogenous intruding pathogens. Puberty is associated with a significant alteration in the oral microbial ecology around the teeth as a result of hormonal changes (hormones such as oestrogen, and serum proteins significantly stimulate growth of Porphyromonas and Treponema species [Darby and Curtis, 2001]). 
The Role of Microorganisms in the Development and Progression of Dental Caries and Periodontitis

The 2 major oral diseases, dental caries and periodontal diseases, are usually referred to as oral infectious diseases both associated with microorganisms in the dental biofilms.

\section{Dental Caries}

Dental caries became considered as an infectious and transmittable disease as a result of experimental studies in rodents in the middle of the 20th century [Fitzgerald et al., 1960]. For decades numerous attempts have been made to prove that specific streptococci are the cause of dental caries [Hamada and Slade, 1980; Loesche, 1986]. However, no single microorganism or a combination of specific bacteria has proved to have predictive value for dental caries clinically or epidemiologically [Nyvad and Fejerskov, 1997; Hausen, 2003; Beighton, 2005; Mejare et al., 2014]. Others have suggested that caries lesion formation should be considered as the net outcome of metabolic events taking place in the dental biofilm covering any site in the dentition [von der Fehr et al., 1970].

An entirely clean tooth surface will, within minutes after exposure to the oral environment, be covered by salivary glycoproteins, which then over the following $24 \mathrm{~h}$ gradually become covered by a dental biofilm, which continues to grow by multiplication and "mature" if left undisturbed for weeks [Nyvad and Fejerskov, 1989]. The commensal microbiota within the dental biofilm is metabolically active and exhibits fluctuations in $\mathrm{pH}$ at the interface between the mineral surface of the tooth (enamel or cementum/dentine) and the biofilm and results in a temporary disturbance in the physicochemical equilibrium between tooth mineral and surrounding fluid [Fejerskov and Larsen, 2015]. The microbial composition of a mature dental biofilm is fairly stable, but there are constant multiple small fluctuations in the $\mathrm{pH}$ [Fejerskov et al., 1992], lower $\mathrm{pH}$ favouring demineralization, while raised $\mathrm{pH}$ favours deposition of mineral. When exposed regularly to fermentable carbohydrates in the diet, the fluctuations in $\mathrm{pH}$ at the surface are amplified, with a tendency for a predominance of low $\mathrm{pH}$. In the presence of such stimuli, the development of a predominantly acidic environment will favour the growth of aciduric streptococci in the biofilm [Welin-Neilands and Svensäter, 2007].

As mineral loss at a site of demineralization continues, the enamel may become fragile over time and can become irreversibly ruptured to form a cavity, exposing the un- derlying dentine. The resultant cavity is rapidly filled with the dental biofilm, and demineralization of the dentine may progress. The formation of deep cavities may produce adaptations in the composition of the biofilm as a local micro-environment of low $\mathrm{pH}$ will favour particular aciduric microorganisms.

Some microorganisms may penetrate the exposed dentinal tubules and the partly dissolved outer layers of the carious dentine, whether in a cavity or on an exposed root surface [Nyvad and Fejerskov, 1987]. While technically one might refer to this as "infected dentine," it is not the invading bacteria that cause further tissue dissolution. The ongoing mineral dissolution is a consequence of acidogenic products of metabolic activity in the biofilm, which result in development of a lowered $\mathrm{pH}$. Where the biofilm is disturbed or removed from such sites, there is a greater likelihood of a gain of mineral deposition partly due to enhanced mineralization caused by odontoblasts within the pulpodentinal organ [Frank and Vogel, 1980] and to some extent as a result of the presence of saliva being supersaturated with respect to hydroxyapatite. At any stage of lesion development further progress can be arrested, so long as the dental pulp remains vital, by removing as much of the microbial deposits as possible regularly [Kidd et al., 2015].

\section{Periodontal Disease}

Periodontal diseases comprise all inflammatory gum diseases. The aetiology and definitions of periodontal diseases have been subject to considerable debate for many decades [Spangler et al., 2012; Lopez et al., 2015]. Much confusion arises because it is frequent to combine gingivitis (gingival inflammation with no loss of periodontal attachment) with signs of inflammation in gingiva associated with loss of attachment [Greene, 1963]. In the presence of plaque around the teeth, most individuals exhibit gingival inflammation at several sites in the oral cavity. In the 1960s, a series of small experimental studies were conducted on dental students who were asked to refrain from oral hygiene for several days. These studies indicated that as dental biofilm (designated plaque) is allowed to remain undisturbed on the teeth, the surrounding gums developed inflammation [Löe et al., 1965; Theilade et al., 1966]. When oral hygiene was reinstituted, the inflammation gradually resolved. As periodontal breakdown (loss of attachment) is usually accompanied by gingival inflammation, it was thought that gingivitis (caused by bacteria) would invariably result in periodontitis if left untreated. This paradigm became dominant in periodontology for almost half a century [Baelum and Lopez, 2013] and was 
the explanation for the claim that periodontitis is an infectious disease. For decades microbial studies have therefore searched for the microorganisms involved in, and thought to cause, periodontal breakdown [Dahlen, 1993; Haffajee and Socransky, 1994; Socransky and Haffajee, 1994; Loesche and Grossman, 2001]. This has resulted in some cases in the use of various antimicrobial treatments combined with mechanical removal of biofilm and calculus [Charalampakis and Dahlen, 2014] as the basis for treatment, but with a limited long-term effect.

There have been relatively few population-based studies on the prevalence of periodontal diseases and even fewer on the natural history of the diseases [Baelum et al., 1996; 1997a]. These studies indicate that the prevalence and severity of periodontal breakdown populations in different countries is similar [Löe et al., 1986; Baelum et al., 1988, 1996, 1997a, 2003; Pilot, 1998; Timmerman et al., 2000; Kvarnvik et al., 2016]. In population-based studies, there appears to be little or no association between the amount of plaque and calculus and the severity of periodontal breakdown exhibited. Periodontal breakdown appears to progress with age in all populations and generally asymptomatically.

It appears that, if left undisturbed, the dental biofilm is associated with gingival inflammation and, over time, with the gradual recession of the gums and the formation of periodontal pockets, especially proximally (between the teeth). It is possible that in proximal sites, the loss of attachment creates a micro-environment, which influences changes in the composition of the biofilm favouring the predominance of anaerobic bacteria [Marsh, 2003]. The essential characteristic of periodontitis appears to be that of gradual recession with age of the gingival margins on buccal and lingual surfaces, with only rare occurrences of deep periodontal pockets on these surfaces, whereas interproximal sites deep pocketing is more frequent [Baelum et al., 1988, 1996, 1997a].

The dynamics and bursts of activity within the subgingival microbiota are associated with bacterial growth and release of metabolites in a slightly alkaline environment. In this anaerobic environment, the bacterial proteolytic activity prevails and produces a cascade of metabolites during growth, such as organic acids, ammonia and hydrogen sulphide. Hydrogen sulphide, which is an end product of proteolytic metabolism, can be produced by a number of oral anaerobic bacteria [Basic et al., 2015]. Hydrogen sulphide-producing bacteria have been shown to be prevalent in periodontal pockets, resulting in an enhanced secretion of pro-inflammatory cytokines [Basic, 2017].
Severe loss of attachment in adults and the elderly in most populations is found amongst 10-15\% [Dye, 2012; Kassebaum et al., 2014]. The existence of a small proportion of individuals having advanced loss of attachment has been interpreted by some as being evidence of risk groups. The driving force in these discussions has been the search to identify, at an early age, the factors that trigger oral disease later in life [Gomez and Nelson, 2017], exemplified by finding that healthy children from 3 months old already harbour potentially cariogenic bacteria, which increase in abundance with age [Gizani et al., 2009; Cephas et al., 2011; Lif Holgerson et al., 2015]. It has thus been suggested that a combination of extrinsic and intrinsic factors determines oral disease phenotypes later in childhood [Gomez and Nelson, 2017]. Similarly, the so-called red complex bacteria ( $P$. gingivalis, $T$. forsythia, Treponema. denticola) [Socransky et al., 1998] have been used in risk evaluation studies for prediction and prognosis (after treatment) of subsequent progression of periodontitis [Charalampakis et al., 2013].

However, with the possible exception of a highly virulent clone of $A$. actinomycetemcomitans [Högberg et al., 2014], no study has so far been able to predict future disease development or progression of either caries or periodontitis by the identification of a single microbial factor. Consequently, the aetiological role of specific bacteria in the development and progression of the major oral diseases is still unclear. Research hitherto suggests that the microbiome comprising resident oral bacteria (commensals) is necessary for disease development and progression, but it is unclear which specific microorganisms constitute the "culprits."

There is limited evidence that any particular combination of microorganisms is responsible for periodontal destruction. Much attention was drawn to the red and orange complexes that were statistically more associated with periodontitis than other bacteria found by DNADNA hybridization [Socransky et al., 1998] and were included in several textbooks [Lindhe et al., 2003; Marsh and Martin, 2009; Dahlen et al., 2012]. Other bacteria or bacterial combinations have also been tested [Dahlen and Leonhardt, 2006; Perez-Chaparro et al., 2014] and were found to be associated with the disease (gingival inflammation and pocketing) but the aetiological role of bacteria in the development and progression of periodontitis is still unclear [Meyle and Chapple, 2015]. 
Fig. 1. Simulation of random fluctuations of plaque $\mathrm{pH}$ over time.

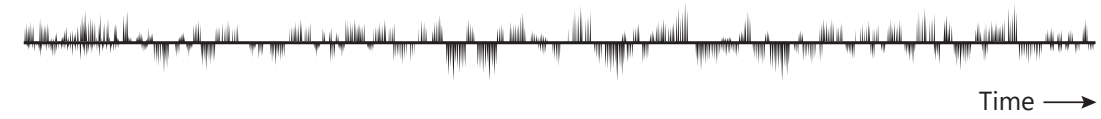

\section{An Alternative Perspective on the Aetiology of Caries and Periodontitis}

The microbiome is implicated in the development and progression of both dental caries and periodontitis (gingival inflammation and periodontal breakdown), but the precise mechanism by which these occur has not hitherto been understood. Dental caries and periodontitis have been considered as distinct diseases around which professional and research disciplines have developed. Yet each disease is associated with the same microbiome comprising predominantly commensal microorganisms.

With more than 700 species of microorganisms and some 19,000 phylotypes that make up the dental biofilm, and with so many other factors that are associated with the progression or retardation of disease processes (such as individual and cultural behaviours, variations in oral hygiene, variations in diet, salivary secretion, host immunological responses, etc.) it is not possible to state with any precision what exactly is happening at any given moment at the interface between the biofilm and the hard tissues (enamel and dentine) or between the biofilm and the periodontal tissues.

While laboratory and experimental studies have investigated the response of dental tissues to stimuli under precise and stable conditions that have provided invaluable information about the many determinants involved in the pathogenesis of caries and periodontitis, they do not necessarily explain the variations and distributions of the disease observed in epidemiological or clinical studies. This is because in real life, the processes involved are complex, with wide variations in the number and types of determinants involved but also in their relative influence. Building a deterministic model, it has been argued, is not feasible because the determinants themselves can only be measured at best as proxy variables. The problem is exacerbated by the fact that the inputs are also highly variable or "noisy" [Manji et al., 1991].

In research, the noise itself is usually controlled for in order that one or other determinant can be identified. Manji et al. [1991] proposed that instead of controlling for the noise, suppose one were to consider instead the noise itself? They proposed that since it is impossible to know what is happening at any given moment within the biofilm it is reasonable to consider what is occurring as effectively random. Poorly understood and complex phenomena such as caries and periodontitis can potentially be trivially explained by random process theories. Indeed, an explanatory model can be developed that requires only the assumption of the existence of noisy metabolic outputs of commensals within the dental biofilm.

\section{The Biofilm and the Response of the Dental Hard}

Tissues

The model proposed by Manji et al. [1991] can be summarized as follows. The biofilm comprises several hundred species of commensal organisms in which there are an indeterminate number of microorganisms engaged in life-sustaining metabolic activities. Assuming that in a healthy individual the nutrient supplies to these microorganisms are sufficient for their normal metabolism and that the host's immune system is healthy and functional, the $\mathrm{pH}$ of the products of metabolic activities at the surface of the dental hard tissues will in some cases be acidic, some neutral, others alkaline. In the absence of sufficient information about exactly is happening at any given time, the activity can be considered to be effectively random.

Manji et al. [1991] developed a random effects model for describing caries lesion development over time. They generated a series of random numbers ("pH values") using a computer over an arbitrary period, which we have reproduced here (the magnitude of the values is neither important here and may be considered large or small, nor is the length of time important here). The parameters were set so that there was an equal probability of positive or negative values. The pattern of random fluctuations appears as shown in Figure 1. This is what in physics is referred to as white noise.

We know that the lowering of $\mathrm{pH}$ favours demineralization, whereas the raising of $\mathrm{pH}$ favours remineralization. The dental hard tissues respond to these fluctuations in $\mathrm{pH}$ by accumulating ("integrating") the noise to pro- 


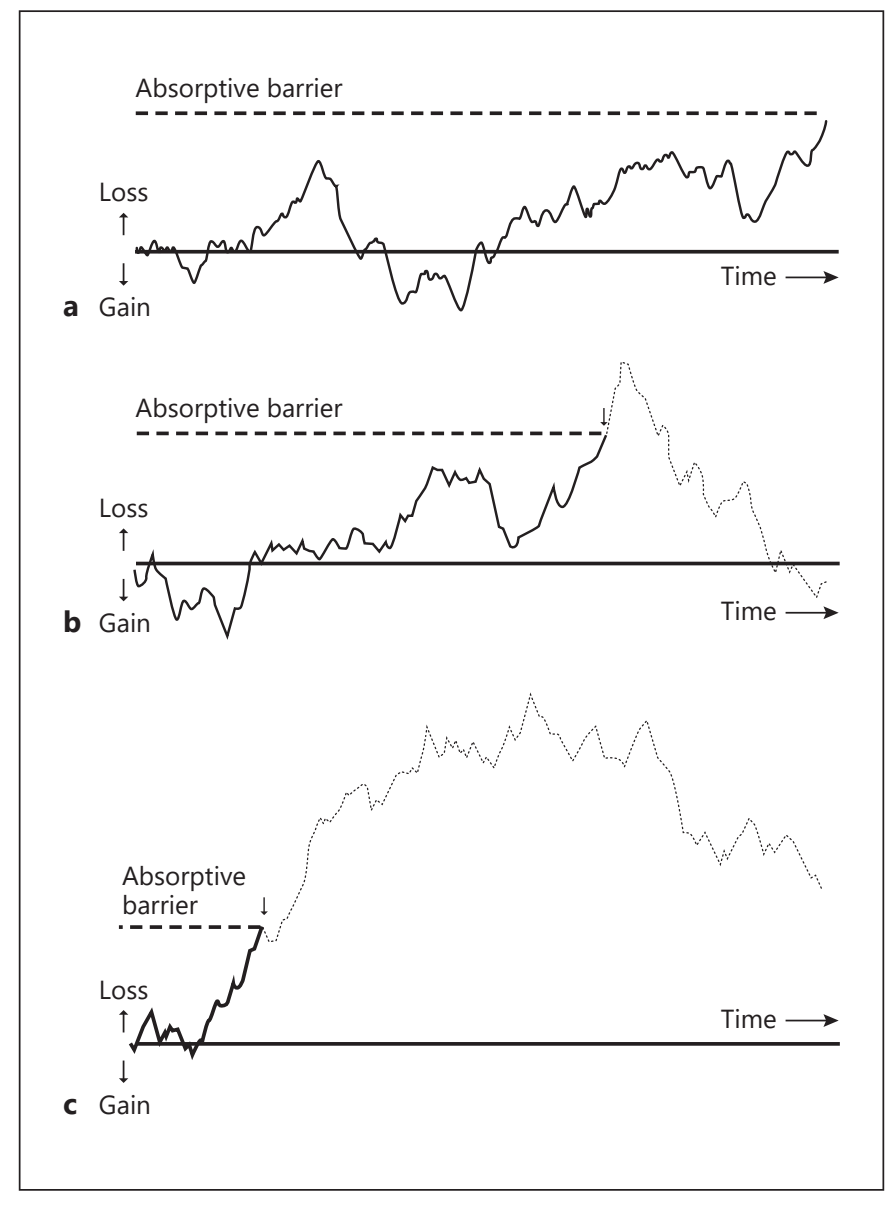

Fig. 2. a-c Three examples of a potentially infinite series showing erratic loss and gain of minerals from the hard tissues caused by accumulation of (integrating) the effects of small random $\mathrm{pH}$ fluctuations (noise) such as illustrated in Figure 1. The solid horizontal line in each case represents the "origin," while the dashed horizontal line represents the position of an arbitrary absorptive barrier. Note how loss and gain occur erratically in each case, the absorptive barrier being reached at different times (and in a, not at all). The path of these processes, had it been allowed to continue without an absorptive barrier, is shown as a dotted line (after Manji et al. [1991]).

duce random episodes of de- and remineralization. In effect, the caries process will behave like integrated white noise, that is, as a Weiner process, or what in physics was described by Einstein [1926] as Brownian motion. The effect of adding together (integrating) the fluctuations such as those shown in Figure 1 is to produce random, often substantial fluctuations in the outcome, that is loss or gain of mineral content.

The differences between the 3 graphs (Fig. $2 \mathrm{a}-\mathrm{c}$ ) illustrated here are entirely the result of the series of random number that happened to be generated in each instance.
What is noteworthy is that these substantial fluctuations occur entirely as a result of accumulating random noise and not as a result of any external inputs.

Loss of mineral from the enamel cannot, of course, occur indefinitely. Once a sufficient degree of demineralization has occurred, a "point-of-no-return" is reached when, for example, a cavity forms. The point of no return can be modelled as a Weiner process with a single absorptive barrier [Cox and Miller, 1987].

The cumulative probability distribution curves generated by the Weiner process with a single absorptive barrier closely approximate the prevalence of caries at a given surface that can be observed from cross-sectional epidemiological surveys of populations with an age range from the eruption of the permanent dentition to old age [Gadegaard and Fejerskov, 1983; Glass et al., 1987; Luan et al., 1989; Manji et al., 1989, 1991; Manji and Fejerskov, 1994; Fejerskov et al., 1994]. The model predicts that there will be few surfaces affected immediately after eruption, but in those slightly older, there is an almost linear relationship with increasing age.

The hazard function of the Weiner process with a single absorptive barrier suggests that in the period immediately after eruption, no cavities are likely to form but that the hazard of a cavity forming increases rapidly thereafter (Fig. 3). Subsequently, the longer a surface survives without having developed a cavity, all other things being equal, the less likely a cavity will subsequently form. In other words, the early period after eruption is the period of greatest risk. This is consistent with epidemiological features of caries [Kassebaum et al., 2015].

The model described gives expression to the concept of caries as a process, and appears to fit well with, and possibly accounts for, the phenomenon of erratic loss and gain of mineral that is characteristic of caries. It suggests that de- and remineralization can occur as a consequence of the random fluctuations of $\mathrm{pH}$ that are a result of integrating the noise of normal metabolic activities of commensal organisms in the oral microbiome if allowed to continue undisturbed over a sufficient period of time.

Nevertheless, in the presence of factors that increase or decrease the likelihood of the absorptive barrier being reached (cavitation) can be built into the model in the form of a "drift" in the probability density of the Weiner process. A positive drift would increase the probability of a given absorptive barrier being reached in a given time, whereas a negative drift would reduce that probability. Factors that would increase the drift include, for example, consumption of sugars and other fermentable carbohydrates that increase the production of acids. Factors such 


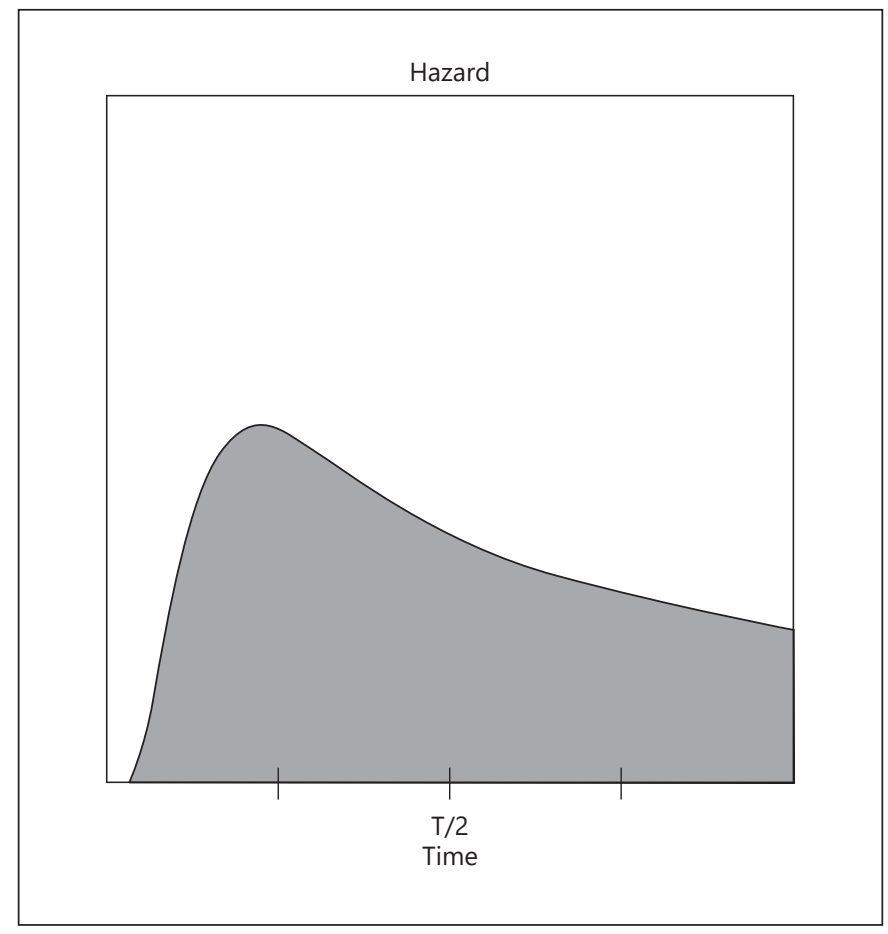

Fig. 3. The hazard function for the model shows that the greatest risk of cavity formation occurs in the period shortly after eruption, but after reaching a peak, the longer a surface survives without developing a lesion, the less likely that one will subsequently form. Note, the units of a hazard function are time - 1 (after Manji et al. [1991]).

as the presence of fluorides in the oral fluids (which enhance the supersaturation with respect to fluorhydroxyapatite), or regular mechanical disturbance of the microbiota (brushing of teeth), would reduce the drift. The model does not negate the findings of research that have identified various "determinants" of dental caries except to suggest that these factors principally influence the probability of cavity formation over a given time rather than being a "causal" factor. The effect of drifts is illustrated in the probability distribution curves shown in Figure 4.

Where there are deep pits or fissures in the tooth surface, a localized adaptation of the microbiota occurs resulting in a predominance of aciduric microorganisms [Hedenbjörk-Lager and Ericson, 2013; Dige et al., 2014].

Interestingly, Manji et al. showed that the model predicted the apparently enigmatic findings in the Netherlands fluoridation studies [Backer Dirks et al., 1961; Marthaler, 1981; Groeneveld, 1985] where the effect of water fluoridation was most pronounced when caries was diagnosed at cavity level, whereas when early enamel demin-

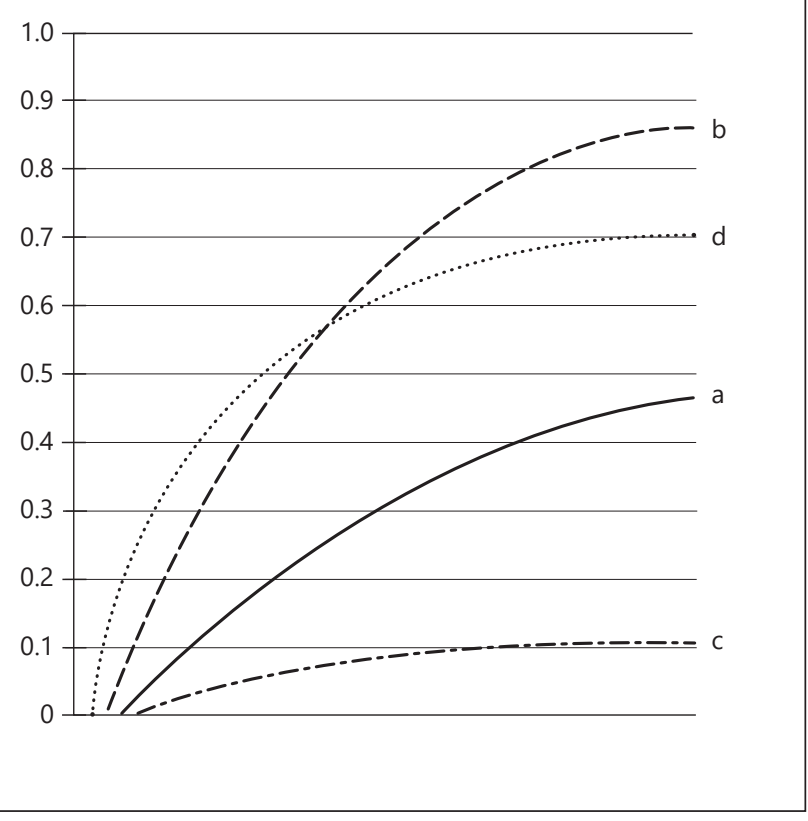

Fig. 4. Four cumulative probability distribution curves showing the probability of a given absorptive barrier being reached within an arbitrary time T. Line a: with no drift; line b: with a positive drift; line $c$ : with a negative drift of the same magnitude as in line b; line $\mathrm{d}$ : with no drift, but doubling of the standard deviation relative to line a (after Manji et al. [1991]).

eralized lesions are included in the diagnosis, there would be no significant differences.

To summarize, Manji et al. [1991] showed that demineralization and remineralization of the hard tissues can occur entirely as a result of the integration of the noise of $\mathrm{pH}$ fluctuations within the dental microbiome which are themselves the outcome of normal metabolic activities of commensal microorganisms. The probability of cavitation occurring depends on the length of time the microbiome remains in contact with the dental hard tissues undisturbed as well as on the influence of factors that affect the drift. For caries to occur only the assumption is required that there is a multitude of commensal microorganisms carrying out normal metabolic activities, and it does not require assumptions about changes in the composition of the biofilm or the presence of putative pathogens. Cavities are unlikely to form in the early period after eruption, but thereafter there is a linear relationship with age. However, the longer a site survives without cavitation, the less likely it is that a lesion will form. 


\section{The Biofilm and the Response of the Periodontal} Tissues

Let us now consider the same dental biofilm that is not merely in contact with the dental hard tissues, but also in contact with the gingival tissues. We can postulate that there are normal products of microbial metabolism some of which stimulate irritation of the gingival tissues, while others are neutral, and perhaps others that stimulate immunological responses of the tissues, leading to repair/ regeneration of the tissues and resolution of inflammation. As in the model proposed by Manji et al. [1991] in relation to dental caries, we can assume that these are effectively random (they may not necessarily be random, but given that we have little knowledge of the nature of all the multiple events that occur within the microbiota, we can treat these as effectively random or at least an approximation).

The response of the gingival tissues will be based on integrating the white noise within the biofilm, that is, they will behave as a Wiener process/Brownian motion. The effect of integration would be the production of random, unpredictable, often substantial inflammatory responses as well as recovery from the inflammation. These events would occur as a direct result of the random noise that occurs constantly within the microbiota in contact with the gingival tissues, assuming that the microbiota is left undisturbed, and would manifest themselves clinically as random fluctuations of inflammation and recovery (resolution of the inflammation).

So, what evidence is there to support the idea that the gingival tissues would necessarily behave in such a manner? It is customarily held that plaque "causes" gingival inflammation and bleeding. This idea has its origins in the results of experimental gingivitis studies conducted by Löe et al. [1965] and Theilade et al. [1966]. The studies were based on individuals desisting from oral hygiene for periods, and the accumulation of plaque around the mouth of the individual related with the presence of gingival inflammation exhibited in the mouth of the individual, but not necessarily at the same site at which plaque accumulation occurred.

However, subsequent experimental gingivitis studies [Danielsen et al., 1989, 1990] have thrown a different light on what is happening when the presence of plaque at a given site is related with the presence or absence of inflammation at that same site. Danielsen et al. [1989] found that there was no correlation between the presence of plaque at a specific site and the presence of inflammation at that same site. Furthermore, the gingival status of a single site was found to be a poor predictor of its status on subsequent occasions. (The study was based on 42 individuals who were given thorough oral hygiene at the start of the study, followed by a period of 14 days when they abstained from oral hygiene. This was followed by thorough prophylaxis and the reinstatement of oral hygiene for the subsequent 10 days.)

Danielsen et al. [1989, 1990] found that when plaque was allowed to accumulate, sites were found to convert from non-inflamed status to inflamed status as well as from inflamed status to non-inflamed status. In other words, there was both a tissue reaction in the form of inflammation but also in the form of recovery, and these appeared to have occurred randomly. The same phenomenon was found once thorough oral hygiene had been reinstituted.

The studies found that the proportion of inflamed sites converting to non-inflamed status (recovery) was greater than the proportion of non-inflamed sites converting to inflamed status at any given time. The estimated incidence rate remained fairly constant during both the plaque accumulation phase and the oral hygiene phase, whereas the estimated recovery rates were considerably lower during the plaque accumulation phase compared to the oral hygiene phase. The steady-state prevalence derived from the estimated incidence and recovery rates were quite similar to the actual findings after 14 days of plaque accumulation as well as in the subsequent 10 days of thorough oral hygiene. Since the dental biofilm re-establishes itself within $24 \mathrm{~h}$ after the teeth have been cleaned, thorough oral hygiene should not be equated with an absence of the microbiome and the associated metabolic activities of the commensals within it. Thus, the rate at which new sites exhibited gingival inflammation remained more or less the same during the poor oral hygiene phase as when the teeth had been cleaned.

The often cited clinical observations of an apparent association between plaque accumulation and gingival inflammation that Löe et al. [1965] and Theilade et al. [1966] and others have reported appears to be accounted for not so much because the presence of plaque at a given site is correlated with the presence of inflammation at that site. Rather, it seems that it is because of a resultant reduction in the capacity of the tissues to recover from inflammation when exposed to prolonged exposure to plaque.

The existence of a reduced recovery rate and therefore a persistence of inflammation in the presence of the accumulation of plaque cannot, we would suggest, continue indefinitely. At some point, breakdown of the gingival collagen fibres will occur. Since prolonged exposure to plaque accumulation appears to inhibit the capacity of the 
tissues to recover, it is likely that over time, there will be a gradual loss of attachment as further breakdown of collagen fibres occurs.

We suggest that this phenomenon can be modelled as a Weiner process with a single absorptive barrier, just as Manji et al. [1991] proposed in relation to the development of dental caries, which we described above.

Given the statistical properties of such a process, we would expect that cumulative probability distribution curves of loss of attachment at a given surface would be similar to those observed in cross-sectional epidemiological studies, and that there would be few surfaces affected in the early period after eruption of the permanent dentition, but in those older, there will be an almost linear relationship with increasing age. The hazard function of a Weiner process with a single absorptive barrier predicts that the longer a site survives without loss of attachment, the less likely it will be that there will be loss of attachment.

These features are consistent with the results of epidemiological studies of populations from young to old age [Baelum et al., 1988; 1996; 1997b; Lopez et al., 2011]. The cumulative distribution curves of loss of attachment are similar to those predicted by the model. Those aged below 25 years exhibit very few sites with loss of attachment, whereas above that age there appears to be an almost linear relationship with increasing age, with about $10-15 \%$ having loss of attachment $\geq 4 \mathrm{~mm}$ amongst the oldest age groups. The relationship between loss of attachment and age in these studies was much clearer when advanced loss of attachment ( $\geq 4 \mathrm{~mm})$ is considered than when any degree loss of attachment $(\geq 1 \mathrm{~mm})$ is considered. This phenomenon is similar to that which we discussed above in relation to caries where the differences between caries in fluoridated zones and those in non-fluoridated zones were more manifest when caries had advanced to cavitation, than when early lesions are included in the diagnosis.

The model suggests that loss of attachment can occur as a result of the integration of the noise created by the normal metabolic activities of commensal microorganisms within the dental microbiome. Thus, it may not be necessary to postulate the existence of changes in the composition of the microbiome, or to postulate the existence of putative periodontal pathogens, for loss of attachment to occur. Of course, there may be factors that can increase or decrease the probability of loss of attachment occurring, creating a drift in the probability distribution, but such factors are not essential for loss of attachment to occur over time.

Caries and Periodontitis
There has been much debate in the past as to whether periodontal breakdown at a given site occurs in a relatively uniform linear fashion [Löe et al., 1986] or whether the disease progresses in bursts and remissions [Socransky et al., 1984]. As Manji and Nagelkerke [1989] have shown, however, these are not contradictory phenomena - they are both compatible with a stochastic model such as we have described above.

Epidemiological studies of periodontal disease indicate that pocket formation occurs predominantly in interproximal zones [Baelum et al., 1988, 1996, 1997b; Lopez et al., 2011]. The prevalence of deep pockets is apparently relatively rare in all age groups, accounting for around $10-15 \%$ in those above 50 years of age. It is possible that where there has been a loss of attachment in these zones, often accompanied with oedematous swelling of the gingival tissues, a micro-environment might develop that results in the predominance of anaerobic microorganisms. The existence of such an adaptation does not negate the continued existence of noise created by the metabolic activities of microorganisms within the microbiota, and such adaptations would constitute a drift affecting the probability of breakdown over a given period of time.

The observation from cross-sectional studies of a small proportion of individuals having advanced loss of attachment has frequently been considered as evidence of the existence of risk groups in the population. While there may be certain groups that are at higher risk than others, it is only possible to identify such groups through prospective longitudinal studies [Manji and Nagelkerke, 1990]. The problem arises because of the need to distinguish between risk and outcome. Risk is the probability of an outcome rather than the outcome itself: when tossing a coin, for example, the probability of heads or tails is fixed (i.e. 0.5), but the outcome varies each time one tosses a coin. It does not matter whether the outcome is the result of intrinsically random events or the influences on the outcome are many and unknown, turning a theoretically deterministic event into an effectively random case. If cross-sectional epidemiological studies in different population groups indicate that only about $10-15 \%$ of the older individuals exhibit severe loss of attachment [Baelum et al., 1993, 1997b], these findings do not necessarily indicate that there are the equivalent proportions of people in each population who are at high risk. The results only suggest that in each of these populations loss of attachment progresses slowly. Such outcomes are consistent with the probability distribution anticipated by the model which would predict that not everyone would be 
expected to experience severe loss of attachment and only a small minority would be expected to show such signs. Variations in outcome (levels, distributions, etc.) will say little about variations in risk. Moreover, there is a limit to what can be predicted, even if we have growing amounts of information about the possible risk factors involved, owing to the intrinsic randomness or unpredictability of the inputs [for further discussion, see Manji and Nagelkerke, 1990].

\section{Discussion}

Both caries and periodontitis are diseases which can progress slowly lifelong. They are both associated with the presence of a dental biofilm in which the metabolic activities of the microbiota may, over time, result on the one hand in the gradual demineralization of the hard dental tissues and on the other, in the gradual recession of the gums with, in some instances, the formation of deep gingival pockets at certain sites. We have illustrated here how both dental caries and periodontitis can occur as a result of the normal (effectively random) metabolic activities of commensal microbiota in the dental biofilm, even in the absence of factors that increase or decrease the probability of their progression. This happens because the tissues integrate the effect of the noise of the metabolic activities within the biofilm. Since the microorganisms involved are commensals, that is to say, they may be considered to be a constitutive part of the holobiont, both caries and periodontitis might be considered "natural," even if, when left unchecked over sufficiently long periods of time, the underlying processes can result in the unpredictable development of pathologies. Since it is impossible (nor indeed desirable) to permanently eliminate the dental biofilm, the processes occurring within it cannot be "prevented." The underlying processes that lead to caries and to periodontitis are similar - the noise within the biofilm - the distinction between the 2 diseases is a function of how the tissues (dental hard tissues or the marginal periodontium) integrate the noise within the biofilm.

Even though the processes that lead to these pathologies may be similar, the likelihood of cavitation or loss of attachment occurring will be influenced by determinants that can influence the drift. The stochastic model outlined here does not preclude the role of determinants that affect progression (such as, in the case of caries, the frequency and composition of fermentable carbohydrates in the diet, the presence of fluoride locally, etc., or in the case of periodontitis, for example, smoking, general health, and the dominance of potential periodontopathogens within the biofilm), but the processes leading to cavitation and loss of attachment can nevertheless occur in the absence of such determinants.

The model discussed here provides, we believe, simple and parsimonious explanations for a number of phenomena that have hitherto proved difficult, or have required complex arguments, to explain. It offers one way in which the variability, which characterizes the complex ecosystem associated with both caries and periodontitis may be considered a subject of interest for enhancing our understanding of their pathogenesis and epidemiology. In most studies of the pathogenesis and epidemiology of dental caries and periodontitis, efforts are made to control for, minimize, or even ignore the noise that characterizes the complex ecosystem within the biofilm. What this model offers is one way in which the noise itself may be considered the subject of attention. The model may offer a potentially unified theory for both caries and periodontitis.

Because both caries and periodontitis are associated with the presence of the oral microbiome, both are amenable to control relatively easily through regular removal of plaque - regular toothbrushing. Knowledge of the role of other determinants can enable public health policies to be implemented that reduce the probability of progression to pathology. For example, for caries, the use of fluoride toothpastes can be encouraged to reduce the probability of cavity formation, and public policies that discourage corporations from promoting harmful products containing refined carbohydrates, especially in low socioeconomic neighbourhoods, where the cheapest goods available for consumption contain sugars [Meier et al., 2017]. In more affluent communities where resources for health care are made available, such as those in Scandinavia, the combination of toothbrushing with a fluoride toothpaste, topical fluoride application, restriction of intake of fermentable carbohydrates [Fejerskov et al., 2013; Hugoson et al., 2008; Norderyd et al., 2015a], and by changing the oral health care knowledge practices of a population [Norderyd et al., 2015b] have been found to be successful ways of controlling caries and enabling populations to maintain a natural functional dentition for life [Fejerskov et al., 2013].

In relation to periodontitis, where individuals perform thorough oral hygiene daily, the proportion of persons with inflamed gingiva decreases significantly and the proportion of periodontally healthy individuals increases [Hugoson et al., 2008]. These authors reported that over a period of 30 years a random sample of adults and elderly subjects demonstrated a significant improvement in 
periodontal health but the proportion of individuals with advanced periodontal destruction remained unchanged despite all the efforts of scaling and polishing the dentitions and having access to periodontal specialists.

Dental caries and periodontitis can both be controlled by non-invasive and non-surgical interventions. These most common oral diseases are both reversible and, as pointed out by Cohen et al. [2017a, b], "in most cases, can be controlled by individuals and communities using simple measures." The progress of dental decay can be arrested even in teeth with open cavities provided the pulp has not become infected. The use of dentists who have been trained for some 4-6 years to undertake such simple measures seems inappropriate.

Studies of populations having little or no access to dental care show that despite poor oral hygiene, most people keep most of their teeth for most of their lives. If only $10-15 \%$ of the population over 50 years of age suffer from severe periodontal breakdown, with the possibility that some of them may lose a few teeth as a consequence, the question inevitably arises whether a strategy of offering periodontal scaling and polishing to the whole population is cost effective or justified, especially if such treatments do not necessarily arrest the development of advanced periodontal breakdown amongst a small minority.
Mass preventive interventions, such as vaccination and immunization programmes, are clearly important in the case of life-threatening communicable diseases, since they ensure that the society as a whole will be protected. But the decision to implement such programmes is a political one. Should not governments create a health system which provides support to all from birth to grave as a means of prevention of all non-communicable diseases such as caries, periodontitis, obesity, diabetes, and cardiovascular diseases? Otherwise we will not see a reduction in prevalence of diseases among the most impoverished populations.

\section{Disclosure Statement}

Each of us is an independent researcher with no conflicts of interest. No funding was raised for preparing this paper.

\section{Author Contributions}

All three authors contributed equally to the development and production of this paper.

\section{References}

-Aas JA, Paster BJ, Stokes LN, Olsen I, Dewhirst FE: Defining the normal bacterial flora of the oral cavity. J Clin Microbiol 2005;43:57215732 .

-Adlerberth I, Strachan DP, Matricardi PM, Ahrné S, Orfei L, Åberg N, Perkin MR, Tripodi S, Hesselmar B, Saalman R, Coates AR, Bonanno CL, Panettea V, Wold AE: Gut microbiota and development of atopic eczema in European cohorts. J Allergy Clin Immunol 2007; 120:343-350.

-Adlerberth I, Wold A: Establishment of the gut microbiota in Western infants. Acta Paediatr 2009;98:229-238.

-Aukhil I, Lopatin DE, Syed SA, Morrison EC, Kowalski CJ: The effects of periodontal therapy on serum antibody (IgG) levels to plaque microorganisms J Clin Periodontol 1988;15: 544-550.

Backer Dirks O, Houwink B, Kwant GW: Some special features of the caries preventive effect of water fluoridation. Arch Oral Biol 1961;4: 187-192.

Baelum V, Chen X, Manji F, Luan WM, Fejerskov $O$ : Profiles of destructive periodontal disease in different populations. J Periodontal Res 1996;31:17-26.

Caries and Periodontitis
Baelum V, Fejerskov O, Manji F: Periodontal diseases in adult Kenyans. J Clin Periodontol 1988; 15:445-452.

Baelum V, Lopez R: Periodontal disease epidemiology - learned and unlearned? Periodontol 2000 2013;62:37-58.

Baelum V, Luan WM, Chen X, Fejerskov O: A 10year study of the progression of destructive periodontal disease in adult and elderly Chinese. J Periodontol 1997a;68:1033-1042.

Baelum V, Luan WM, Chen X, Fejerskov O: Predictors of destructive periodontal disease incidence and progression in adult and elderly Chinese. Community Dent Oral Epidemiol 1997b;25:265-272.

Baelum V, Pisuithankan S, Teanpaisan R, Pithpornchaiyakul W, Pongpaisal S, Papapanou PN, Dahlen G, Fejerskov O: Periodontal conditions among adults in Southern Thailand. J Periodontal Res 2003;38:156-163.

Baelum V, Wen-Min L, Dahlen G, Fejerskov O, Xia C: Six-year progression of destructive periodontal disease in 2 subgroups of elderly Chinese. J Periodontol 1993;64:891-899.

Basic A: The Importance of Bacterial Hydrogen Sulfide in the Pathogenesis of Periodontal Diseases; thesis, University of Gothenburg, 2017.
Basic A, Blomqvist S, Carlén A, Dahlén G: Estimation of bacterial hydrogen sulfide production in vitro. J Oral Microbiol 2015;7:e28166.

Beighton D: The complex oral microflora of highrisk individuals and groups and its role in the caries process. Community Dent Oral Epidemiol 2005;33:248-255.

Bessman NJ, Sonnenberg GF: Emerging roles for antigen presentation in establishing host-microbiome symbiosis. Immunol Rev 2016;272: 139-150.

Burne RA: Oral streptococci. Products of their environment. J Dent Res 1998;77:445-452.

Cephas KD, Kim J, Mathai RA, Barry KA, Dowd SE, Meline BS, Swanson KS: Comparative analysis of salivary bacterial microbiome diversity in edentulous infants and their mothers or primary care givers using pyrosequencing. PLoS One 2011;6:e23503.

Charalampakis G, Dahlen G: Rationale for treatment of oral infectious diseases based on a microecological concept. Curr Trends Microbiol 2014;9:1-18.

Charalampakis G, Dahlen G, Carlén A, Leonhardt $\AA$ : Bacterial markers vs clinical markers to predict progression of chronic periodontitis: a 2-year prospective observational study. Eur J Oral Sci 2013;121:394-402. 
Chow J, Lee SM, Shen Y, Khorsravi A, Mazmanian SK: Host-bacterial symbiosis in health and disease. Adv Immunol 2010;107:243274.

-Cohen L, Dahlen G, Escobar A, Fejerskov O, Johnson NW, Manji F: La Cascada declaration. Aust Dent J 2017a;62:258-260.

-Cohen L, Dahlen G, Escobar A, Fejerskov O, Johnson NW, Manji F: Why a radical overhaul of dentistry is needed. Indian J Dent Res 2017b;28:471-474.

Cole MF, Lydyard PM: Oral microbiology and the immune response; in Lamont RJ, Burne RA, Lantz MS, LeBlanc DJ (eds): Oral Microbiology and Immunology. Washington, ASM Press, 2006, chapt 10, pp 201-229.

Costalonga M, Herzberg MC: The oral microbiome and the immunobiology of periodontal disease and caries. Immunol Lett 2014;162: 22-38.

Cox DR, Miller HD: The Theory of the Stochastic Process. Bristol, Arrowsmith, 1987, pp 22-61, 219-223.

Crielaard W: The effects of different antibiotics on salivary microbiome profiles determined by $16 \mathrm{~S}$ rRNA gene amplification sequencing. Microb Ecol Health Dis 2013;24(suppl):5-6.

-Crielaard W, Zaura E, Schuller AA, Huse SM, Montijn RC, Keijser BJ: Exploring the oral microbiota of children at various development stages of their dentition in relation to their oral health. BMC Med Genom 2011;4: 22.

Dahlen G: Role of suspected periodontopathogens in microbiological monitoring of periodontitis. Adv Dent Res 1993;7:163-174.

Dahlen G: Bacterial infections of the oral mucosa. Periodontol 2000 2009;49:13-38.

Dahlen G: Culture-based analysis of endodontic infections; in Fouad AF (ed): Endodontic Microbiology, ed 2. Hoboken, Wiley \& Sons, 2017, chapt 4, pp 51-79.

-Dahlen G, Fabricius L, Holm SE, Möller ÅJR: Interactions within a collection of eight bacterial strains from a monkey dental root canal. Oral Microbiol Immunol 1987;2:164-170.

Dahlen G, Fiehn NE, Olsen I (eds): Oral Microbiology and Immunology. Copenhagen, Munksgaard, 2012.

-Dahlen G, Leonhardt Å: A new checkerboard panel for testing bacterial markers in periodontal disease. Oral Microbiol Immunol 2006;21:6-11.

-Dahlen G, Luan WM, Dahlgren U, Papapanou PN, Baelum V, Fejerskov O: Subgingival bacterial clusters and serum antibody response as markers of extent and severity of periodontitis in adult Chinese. Eur J Oral Sci 2016;124: 179-187.

Dahlgren U: The immune system; in Dahlen G, Fiehn NE, Olsen I (eds): Oral Microbiology and Immunology. Copenhagen, Blackwell Munksgaard, 2012, chapt 2, pp 53-102.
Danielsen B, Manji F, Nagelkerke N, Fejerskov O, Baelum V: Transition dynamics in experimental gingivitis in humans. J Periodontal Res 1989;24:254-260.

Danielsen B, Manji F, Nagelkerke N, Fejerskov O, Baelum V: Effect of cigarette smoking on the transition dynamics in experimental gingivitis. J Clin Periodontol 1990;17:159-164.

Darby I, Curtis M: Microbiology of periodontal disease in children and young adults. Periodontol 2000 2001;26:33-53.

Darveau RP: Periodontitis: a polymicrobial disruption of host homeostasis. Nat Rev Microbiol 2010;8:481-490.

Dewhirst FE, Chen T, Izard J, Paster BJ, Tanner AC, $\mathrm{Yu}$ WH, Lakshamanan A, Wade WG: The human oral microbiome. J Bacteriol 2010;192:5002-5017.

Dige I, Grönkjaer L, Nyvad B: Molecular studies of the structural ecology of natural occlusal caries. Caries Res 2014;48:451-460.

- Dominguez-Bello MG, Costello EK, Contreras M, Magris M, Hidalgo G, Fierer N, Knight R: Delivery mode shapes the acquisition and structure of the initial microbiota across multiple body habitats in newborns. Proc Natl Acad Sci USA 2010;107:11971-11975.

Dye BA: Global periodontal disease epidemiology. Periodontol 2000 2012;58:10-25.

Einstein A: Investigation on the Theory of Brownian Movement. London, Methuen, 1926.

-Fabricius L, Dahlen G, Holm SE, Möller ÅJR: Influence of combinations of oral bacteria on periapical tissues of monkeys. Scand J Dent Res 1982;90:200-206.

-Fejerskov O, Baelum V, Luan W-M, Manji F: Caries prevalence in Africa and the People's Republic of China. Int Dent J 1994;44(suppl 1):425-433.

Fejerskov O, Escobar G, Jössing M, Baelum V: A functional natural dentition for all - and for life? The oral healthcare system needs revision. J Oral Rehabil 2013;40:707-722.

Fejerskov O, Larsen MJ: Demineralisation and remineralization: the key to understanding the clinical manifestations of dental caries; in Fejerskov O, Nyvad B, Kidd E (eds): Dental Caries: The Disease and Its Clinical Manifestations, ed 3. New York, Wiley \& Sons, 2015, pp 155-170.

Fejerskov O, Scheie A, Manji F: The effect of sucrose on plaque $\mathrm{pH}$ in the primary and permanent dentition of caries-inactive and -active Kenyan children. J Dent Res 1992;71:2531.

Fitzgerald RJ, Jordan HU, Stanley HR: Experimental caries and gingival pathologic changes in gnotobiotic rat. Arch Oral Biol 1960;39: 923-935.

Frandsen EV, Pedrazzoli V, Kilian M: Ecology of viridans streptococci in the oral cavity and pharynx. Oral Microbial Immunol 1991;6: 129-133.

Frank RM, Vogel JC: Ultrastructure of the human odontoblast process. Caries Res 1980;14:367380 .
Gadegaard E, Fejerskov O: Epidemiologic Data on Caries and Periodontal Diseases in Tanzania. Aarhus, Royal Dental College, 1983, pp 20-22.

Gizani S, Papaioannou W, Haffajee AD, Kavadia K, Quirynen M, Papagiannoulis L: Distribution of selected cariogenic bacteria in five different intra-oral habitats in young children. Int J Pediatr Dent 2009;19:193-200.

- Glass RL, Alman JE, Chauncey HH: A 10-year longitudinal study of caries incidence rates in a sample of male adults in the USA. Caries Res 1987;21:360-367.

Gomez A, Nelson KE: The oral microbiome of children: development, disease, and implications beyond oral health. Microbiol Ecol 2017;73:492-503.

-Greene JC: Oral hygiene and periodontal disease. Am J Public Health 1963;53:913-922.

-Griffen AL, Beall CJ, Firestone ND, Gross EL, Difranco JM, Hardman JH, Vriesendorp B, Faust RA, Janies DA, Leys EJ: CORE: a phylogenetically curated $16 \mathrm{~S}$ rDNA database of the core oral microbiome. PLoS One 2011;6 e19051.

Groeneveld A: A longitudinal study of prevalence of enamel lesions in a fluoridated and nonfluoridated area. Community Dent Oral Epidemiol 1985;13:159-163.

Haffajee AD, Socransky SS: Microbial etiological agents of destructive periodontal diseases. Periodontol 2000 1994;5:78-111.

Hamada C, Slade HD: Biology immunology, and cariogenicity of Streptococcus mutans. Microbiol Rev 1980;44:331-384.

-Haubek D, Ennibi OK, Paulsen K, Vaeth M, Poulsen S, Kilian M: Risk of aggressive periodontitis in adolescent carriers of the JP2 clone of Aggregatibacter (Actinobacillus) actinomycetemcomitans in Morocco: a prospective longitudinal cohort study. Lancet 2008; 371:237-242.

Hausen H: Caries prediction; in Fejerskov O, Kidd E (eds): Dental Caries. The Disease and Its Clinical Management. Copenhagen, Blackwell Munksgaard, 2003, pp 327-339.

Hedenbjörk-Lager A, Ericson D: Aciduric bacterial communities at three levels in dentin caries. Oral Health Prev Dent 2013;11:359-367.

-Hesselmar B, Sjöberg F, Saalman R, Åberg N, Adlerberth I, Wold AE: Pacifier cleaning practices and risk of allergy development. Pediatrics 2013;131:e1829-e1837.

Högberg CH, Kwamin F, Claesson R, Dahlen G, Johansson A, Haubek D: Progression of attachments loss is strongly associated with presence of JP2 genotype of Aggregatibacter actinomycetemcomitans: a prospective cohort study of a young adolescent population. J Clin Periodontol 2014;41:232-241.

Hugoson A, Sjödin B, Norderyd O: Trends over 30 years, 1973-2003, in the prevalence and severity of periodontal disease. J Clin Periodontol 2008;35:405-414. 
Ivanov II, Littman DR: Modulation of immune homeostasis by commensal bacteria. Curr Opin Microbiol 2011;14:06-114.

Johansson A, Dahlen G: Bacterial virulence factors that contribute to periodontal pathogenesis; in Bostanci N, Belibasakis GN (eds): Pathogenesis of Periodontal Diseases. Berlin, Springer Nature, 2017, pp 1-63.

-Karlsson MR, Kahu H, Hanson LÅ, Telemo E, Dahlgren UIH: Neonatal colonization of rats induces immunological tolerance to bacterial antigens. Eur J Immunol 1999;29109-29118.

Kassebaum NJ, Bernabé E, Dahiya M, Bhandari B, Murray CJL, Marcenes W: Global burden of severe periodontitis in 1990-2010: a systematic review and metaregression. J Dent Res 2014;93:1045-1053.

Kassebaum NJ, Bernabé E, Dahiya M, Bhandari B, Murray CJL, Marcenes W: Global burden of untreated caries in 1990-2010: a systematic review and meta-regression. J Dent Res 2015; 94:650-658.

Keijser BJ, Zaura E, Huse SM, van der Vossen JM, Schuren FH, Montjin RC, ten Cate JM, Crielaard W: Pyrosequencing analysis of the oral microflora of healthy adults. J Dent Res 2008 87:1016-1020.

Kidd E, Fejerskov O, Nyvad B: Infected dentine revisited. Dent Update 2015;42:802-806.

Kilian M, Chapple ILC, Haning M, Marsh PD, Meuric V, Pedersen AML, Tonetti MS, Wade WG, Zaura E: The oral microbiome - an update for oral health professionals. Br Dent J 2016;221:657-666.

Könönen E: Oral colonization by anaerobic bacteria during childhood: role in health and disease. Review. Oral Dis 1999;5:278-285.

-Könönen E, Kanervo A, Takala A, Asikainen S, Jousimies-Somer H: Establishment of oral anaerobes during the first year of life. J Dent Res 1999;78:1634-1639.

Kvarnvik C, Söljegård E, Charalampakis G, Suksu-Art N, Dahlen G: Periodontal disease in a remote Asian population. Association between clinical and microbiological parameters. J Invest Clin Dent 2016;7:246-255.

Lif Holgerson P, Öhman C, Rönnlund A, Johansson I: Maturation of oral microbiota in children with or without dental caries. PLoS One 2015;10:e0128534.

Lindhe J, Karring T, Lang NP: Clinical Periodontology and Implant Dentistry, ed 4. Copenhagen, Blackwell Munksgaard, 2003.

Listl S, Galloway J, Mosey PA, Marcenes W: Global impact of dental diseases. J Dent Res 2015; 94:1355-1361.

LLöe H, Ånerud A, Boysen H, Morrison E: Natural history of periodontal disease in man. Rapid, moderate and no loss of attachment in Sri Lankan laborers 14 to 46 years of age. J Clin Periodontol 1986;13:431-445.

Löe H, Theilade E, Jensen SB: Experimental gingivitis in man. J Periodontol 1965;36:177187.

Loesche WJ: Role of Streptococcus mutans in human dental decay. Microbiol Rev 1986;50: 353-380.
Loesche WJ, Grossman NS: Periodontal disease as a specific, albeit chronic, infection: diagnosis and treatment. Clin Microbiol Rev 2001;14: 727-752.

Lopez R, Dahlen G, Baelum V: Subgingival microbial consortia and the clinical features of periodontitis in adolescents. Eur J Oral Sci 2011;119:455-462.

Lopez R, Hujoel P, Belibasakis GN: On putative periodontal pathogens: an epidemiological perspective. Virulence 2015;6:249-257.

Luan WM, Baelum V, Chen X, Fejerskov O: Dental caries in adult and elderly Chinese. J Dent Res 1989;68:1771-1776.

Manji F, Fejerskov O: An epidemiological approach to dental caries; in Thylstrup A, Fejerskov O (eds): Textbook of Clinical Cariology, ed 2. Copenhagen, Munksgaard, 1994, pp 159-191.

Manji F, Fejerskov O, Baelum V: Pattern of dental caries in an adult rural population. Caries Res 1989;23:55-62.

Manji F, Fejerskov O, Bælum V, Luan WM, Chen $\mathrm{X}$ : The epidemiological features of dental caries in African and Chinese populations: implications for risk assessment; in Johnson NW (ed): Dental Caries: Markers of High and Low Risk Groups and Individuals. Cambridge, Cambridge University Press, 1991, vol 1, pp 62-99.

Manji F, Fejerskov O, Nagelkerke ND, Baelum V: A random effects model some epidemiological features of dental caries. Community Dent Oral Epidemiol 1991;19:324-328.

Manji F, Nagelkerke N: A stochastic model for periodontal breakdown. J Periodontal Res 1989;24:279-281.

Manji F, Nagelkerke N: What can variations in disease outcome tell us about risk? Community Dent Oral Epidemiol 1990;18:106-107.

Marsh PD: Are dental diseases examples of ecological catastrophes? Microbiology 2003;149: 279-294.

- Marsh PD: Dental plaque as a microbial biofilm. Caries Res 2004;38:204-211.

Marsh PD, Devine DA: How is the development of dental biofilms influenced by the host? 2011;38(suppl 11):28-35.

Marsh PD, Martin MV: Oral Microbiology, ed 5. Edinburgh, Churchill Livingstone, 2009.

- Marthaler TM: Interim report on DMF reduction 16 years after the introduction of a preventive program. Community Dent Oral Epidemiol 1981;9:210-214.

Meier T, Deumelandt P, Christen O, Stangi GI, Riedel K, Langer M: Global burden of sugarrelated dental diseases in 168 countries and corresponding health care costs. J Dent Res 2017;96:845-854.

Mejare I, Axelsson S, Dahlen G, Espelid I, Norlund A, Traneus S, Twetman S: Caries risk assessment. A systematic review. Acta Odont Scand 2014;72:81-91.

-Meyle J, Chapple I: Molecular aspects of the pathogenesis of periodontitis. Periodontol 2000 2015;69:7-17.
Norderyd O, Koch G, Papias A, Anastassaki Köhler A, Nydell Helkimo A, Brahm CO, Lindmark U, Lindfors N, Mattson A, Rolander B, Ullbro C, Wärnberg Gerdin E, Frisk F: Oral health of individuals aged $3-80$ years in Jönköping, Sweden, during 40 years (19732013). I. Review of findings on oral care habits and knowledge of oral health. Swe Dent J 2015a;39:57-68.

Norderyd O, Koch G, Papias A, Anastassaki Köhler A, Nydell Helkimo A, Brahm CO Lindmark U, Lindfors N, Mattson A, Rolander B, Ullbro C, Wärnberg Gerdin E, Frisk F: Oral health of individuals aged $3-80$ years in Jönköping, Sweden, during 40 years (19732013). II. Review of clinical and radiographical findings. Swe Dent J 2015b;39:69-86.

Nyvad B, Crielaard W, Mira A, Takahashi N, Beighton D: Dental caries from a molecular microbiological perspective. Caries Res 2013; 47:89-102.

Nyvad B, Fejerskov O: Scanning electron microscopy of early microbial colonization of human enamel and root surfaces in vivo. Scand J Dent Res 1987;95:287-296.

Nyvad B, Fejerskov O: Structure of dental plaque and the plaque-enamel interface in human experimental caries. Caries Res 1989;23:251258

Nyvad B, Fejerskov O: Assessing the stage of caries lesion activity on the basis of clinical and microbial examination. Community Dent Oral Epidemiol 1997;25:69-75.

Perez-Chaparro PJ, Goncalves C, Figueredo LC, Faveri M, Lobao E, Tamashiro N, Duarte P Feres M: Newly identified pathogens associated with periodontitis: a systematic review. J Dent Res 2014;93:846-858.

Pilot T: The periodontal disease problem. A comparison between industrialised and developing countries. Int Dent J 1998;48(suppl):221232

Pussinen PJ, Könönen E, Paju S, Hyverinen K, Gursoy UK, Muumonen S, Knuutila M, Suominen AL: Periodontal pathogen carriage rather than periodontitis determines the serum antibody levels. J Clin Periodontol 2011; 38:405-411.

- Rosier BT, De Jager, Zaura E, Krom BP: Historical and contemporary hypothesis on the development of oral diseases: are we there yet? Front Cell Infect Microbiol 2014;92:1-11.

-Samaranayake LP, Keung Leung W, Jin L: Oral mucosal fungal infections. Periodontol 2000 2009;49:39-59.

Siqueira JF, Rocas IN: Molecular analysis of endodontic infections; in Fouad AF (ed): Endodontic Microbiology, ed 2. Hoboken, Wiley \& Sons, 2017, chapt 5, pp 81-128.

Socransky SS, Haffajee AD: The bacterial etiology of destructive periodontal disease: current concepts. J Periodontol 1992;63(suppl):322331

Socransky SS, Haffajee AD: Evidence of bacterial etiology: a historical perspective. Periodontol 2000 1994;5:7-25. 
Socransky SS, Haffajee AD, Cugini MA, Smith C, Ken RL Jr: Microbial complexes in subgingival plaque. J Clin Periodontol 1998;25:134144.

Socransky SS, Haffajee AD, Goodson JM, Lindhe $\mathrm{J}$ : New concepts of progression of destructive periodontal disease. J Clin Periodontol 1984; 11:21-32.

-Spangler L, Chaudhari M, Barlow WE, Newton KM, Inge R, Hujoel P, Genco RJ, Reid RJ: Using administrative data for epidemiological research: case study to identify persons with periodontitis. Periodontol 2000 2012;58:143152.

Takahashi N, Nyvad B: The role of bacteria in the caries process: ecological perspectives. J Dent Res 2011;90:294-303.

- Tanner AC, Milgrom PM, Kent R Jr, Mokeem SA, Page RC, Riedy CA, Weinstein P, Bruss J: The microbiota of young children from tooth and tongue samples J Dent Res 2002;81:53-57.
The Human Microbiome Project Consortium: Structure, function and diversity of the healthy human microbiome. Nature 2012; 486:207-214.

Theilade E, Wright WH, Jensen SB, Löe H: Experimental gingivitis in man. II. A longitudinal clinical and bacteriological investigation. J Periodontal Res 1966;1:1-13.

Timmerman MF, van der Weiden GA, Abbas F, Arief EM, Armand S, Winkel EG, van Winkelhoff AJ. Van der Velden U: Untreated periodontal disease in Indonesian adolescents. Longitudinal clinical data and prospective clinical and microbiological risk assessment. J Clin Periodontol 2000;27:932-942.

Tinoco EMB, Sivakumar M, Preus H: The distribution and transmission of Actinobacillus actinomycetemcomitans in families with localized juvenile periodontitis. J Clin Periodontol 1998;25:99-105.

Tourneur E, Chassin C: Neonatal immune adaptation of the gut and its role during infections. Clin Dev Immunol 2013;2013:e270301.

-Van Winkelhoff AJ, Rijnsburger MC, van der Velden U: Clonal stability of Porphyromonas gingivalis in untreated periodontitis J Clin Periodontol 2008;35:674-679.
Von der Fehr FR, Löe H, Theilade E: Experimental caries in man. Caries Res 1970;4:131-148.

Wade WG: The oral microbiome in health and disease. Pharmacol Res 2013;69:137-143.

Welin-Neilands J, Svensäter G: Acid tolerance of biofilm cells of Streptococcus mutans. Appl Environ Microbiol 2007;73:5633-5638.

Wilson M: Microbial Inhabitants of Humans. Their Ecology and Role in Health and Disease. Cambridge, Cambridge University Press, 2005.

Xu X, He J, Xue J: Oral cavity contains distinct niches with dynamic microbial communities. Environ Microbiol 2015;192:5002-5012.

Zanoni BC, Gandhi RT: Update on opportunistic infections in the era of effective antiretroviral therapy. Infect Dis Clin North Am 2014;28: 501-518.

Zaura E, Keijser BJ, Huse SM, Crielaard W: Defining the healthy "core microbiome" of oral communities. BMC Microbiol 2009;9:e259. 